\title{
Impact of motivational interviewing-based training in screening, brief intervention, and referral to treatment on residents' self-reported attitudes and behaviors
}

\author{
J Paul Seale ${ }^{1,2^{*}}$, Denice C Clark², Jason Dhabliwala ${ }^{2}$, David Miller ${ }^{3}$, Hunter Woodall ${ }^{4}$, Sylvia Shellenberger ${ }^{1,2}$, \\ J Aaron Johnson ${ }^{1,2}$
}

From International Network on Brief Interventions for Alcohol and Other Drugs (INEBRIA) Meeting 2013 Rome, Italy. 18-20 September 2013

\section{Introduction}

Many medical residents now receive training in screening, brief intervention, and referral to treatment (SBIRT) for alcohol and drugs. Clinician attitudes have been shown to impact SBIRT-related behaviors. Little research has explored the impact of SBIRT training on clinicians' attitudes.

\section{Objective}

To determine whether SBIRT training impacts resident physicians' alcohol-related attitudes and self-reported SBIRT activities.

\section{Methods}

Residents participating in SBIRT training in 4 U.S. primary care residency programs were surveyed during Months 0, 12, and 24. Interventions included training faculty site coordinators, providing residents 6 hours of motivational interviewing (MI)-based SBIRT curriculum per year, and implementing SBI protocols in residency clinics. Impact was assessed using the Short Alcohol and Alcohol Problems Perception Questionnaire (SAAPPQ) and residents' self-reported frequency of alcohol screening, brief interventions (BIs) and use of specific BI components. Analyses assessed changes over time in SAAPPQ total and subscale scores, changes in $\mathrm{BI}$ performance and use of BI components, and the

\footnotetext{
* Correspondence: seale.paul@mccg.org

'Department of Family Medicine, Medical Center of Central Georgia, Macon, GA, USA

Full list of author information is available at the end of the article
}

relationship between attitude scores and frequency of performing BIs and specific BI components.

\section{Results}

Residents' scores on the role adequacy subscale of the SAAPPQ increased significantly between baseline and 12 month survey $(\mathrm{p}<.001)$. This increase was sustained at 24 months $(\mathrm{p}<.001)$. Other subscales and overall SAAPPQ scores did not change. Chi-square tests showed significant increases over time in the frequency of screening at chronic care visits $(\mathrm{p}=.02)$ and in use of BI elements including: providing feedback $(\mathrm{p}=.003)$, advising to cut down/quit ( $\mathrm{p}<.001)$, using $\mathrm{MI}$ techniques to motivate $(\mathrm{p}<.001)$, negotiating a plan $(\mathrm{p}=.01)$, and emphasizing patient strengths $(\mathrm{p}<.001)$. Regression analyses found a significant positive relationship between SAAPPQ scores and both frequency of performing BIs and the use of appropriate BI elements.

\section{Conclusion}

Twelve hours of SBIRT training, when accompanied by faculty training and clinic SBI implementation protocols, has a modest positive impact on resident attitudes and SBIRT behaviors.

\footnotetext{
Authors' details

${ }^{1}$ Department of Family Medicine, Medical Center of Central Georgia, Macon, GA, USA. ${ }^{2}$ Department of Family Medicine, Mercer University School of Medicine, Macon, GA, USA. ${ }^{3}$ Department of Internal Medicine, Wake Forest University Baptist Medical Center, Winston-Salem, NC, USA. ${ }^{4}$ Med Health Family Medicine Residency, Anderson, SC, USA.
}

Published: 4 September 2013 
doi:10.1186/1940-0640-8-S1-A71

Cite this article as: Seale et al:: Impact of motivational interviewing-

based training in screening, brief intervention, and referral to treatment

on residents' self-reported attitudes and behaviors. Addiction Science \&

Clinical Practice 2013 8(Suppl 1):A71.

Submit your next manuscript to BioMed Central and take full advantage of:

- Convenient online submission

- Thorough peer review

- No space constraints or color figure charges

- Immediate publication on acceptance

- Inclusion in PubMed, CAS, Scopus and Google Scholar

- Research which is freely available for redistribution

Submit your manuscript at 